\title{
doispontos:
}

\section{Algazel como sequax Avicennae: a transmissão latina da tese acerca da acidentalidade da existência}

\author{
Algazel as a sequax Avicennae: the Latin transmission of the thesis about the accidental nature \\ of existence
}

\author{
Alfredo Storck \\ Universidade Federal do Rio Grande do Sul - UFRGS ${ }^{1}$ \\ alfredo.storck@ufrgs.br
}

\begin{abstract}
Resumo: Uma das particularidades da recepção do pensamento de Algazel entre os pensadores latinos medievais foi o fato de ele ter sido considerado um sequax Avicennae. As críticas que Algazel direcionou a Avicena não foram conhecidas em um primeiro momento de modo que sua obra influenciou positivamente a recepção do pensamento aviceniano. O objetivo do presente artigo é passar em revista o modo como as versões latinas da Lógica e da Metafísica de Algazel transmitem a tese aviceniana da existência como acidente da essência. O presente artigo será divido em duas partes. Na primeira, defenderemos que a Lógica de Algazel oferece uma caracterização da distinção em termos puramente lógicos ao passo que, na segunda, perguntaremos se a distinção recebe, na Metafísica, uma interpretação ontológica, ou seja, se implica uma distinção real entre essência e existência.
\end{abstract}

Palavras-chave: Algazel Latinus, Avicena Latinus, essência e existência, lógica medieval, metafísica medieval.

\begin{abstract}
One of the distinguishing features of the reception of Algazel's thought among medieval Latin thinkers was the fact that he was considered a sequax Avicennae. Algazel's criticism of Avicenna was not known at first, and his work influenced positively the reception of Avicenna thought in the West. The objective of this article is to examine how the Latin versions of Algazel's Logic and Metaphysics transmitted the Avicenian thesis of existence as an accident of the essence. This paper will be divided into two parts. In the first, we will defend that Algazel's Logic offers a characterization of the distinction in purely logical terms while, in the second, we will ask if the distinction receives, in Metaphysics, an ontological interpretation, that is, if it implies a real distinction between essence and existence.
\end{abstract}

Keywords: Algazel Latinus, Avicena Latinus, essence and existence, medieval logic, medieval metaphysics.

\footnotetext{
${ }^{1} \mathrm{O}$ presente trabalho foi realizado com apoio do CNPq, Conselho Nacional de Desenvolvimento Científico e Tecnológico - Brasil (307054/2017-9).
} 


\section{Introdução}

A recepção no Ocidente latino da obra filosófica de Abū Hāmid Muhammad ibn Muḥammad at-Tüsiyy al-Ġaz $(z) \overline{a l} \bar{l} y$, conhecido entre os latinos como Algazel, foi sem dúvida paradoxal devido a acidentes ligados à sua tradução. Com efeito, o objetivo original de Algazel era criticar diversas teses filosóficas difundidas à época e, para tanto, compôs uma obra dividida em duas partes complementares. A primeira, intitulada Maqâsid al-falâsifa (Os objetivos dos filósofos), buscava apresentar um resumo das posições de al-Fârâbî e especialmente de Avicena. Essa parte foi traduzida para o latim no século XII. Já a segunda, intitulada Tahâfut al-falâsifa ( $A$ incoerência dos filósofos), tinha por objetivo refutar as posições anteriormente apresentadas, pois estariam baseadas na filosofia grega e, segundo o autor, entrariam em contradição com os ensinamentos do islã (BELLO, 1989; MARMURA, 1975; MINNENA, 2014). No entanto, esta segunda parte não foi traduzida para o latim e o resultado foi que o trabalho de Algazel serviu paradoxalmente mais como um instrumento para transmitir as ideias de Avicena do que para as refutar. ${ }^{2}$ A obra de Algazel acabou assim por transmitir aos latinos importantes esclarecimentos sobre o pensamento de Avicena, sobretudo porque a obra de base que serviu de base para o resumo de Algazel não fazia parte da enciclopédia filosófica Kitab al-Shifa (Livro da Cura) e que foi traduzida para o latim também no século XII, provavelmente após $1150{ }^{3}$

No que segue, proporemos uma análise das principais teses relativas à distinção entre essência e existência tal como as encontramos nas partes dedicadas à Lógica e à Metafísica do Maqâsid al-falâsifa de Algazel. ${ }^{4}$ Nestas duas partes, o ponto de partida manteve-se o mesmo: a noção de ens é caracterizada como primitiva e indefinível. Como veremos, o vocabulário das traduções latinas e o modo de argumentação são bastante próximos aos de Avicena, de modo que os latinos não tiveram dificuldade em reconhecer em Algazel um sequax Avicennae.

Assinalemos inicialmente que, segundo o vocabulário da tradução latina, Avicena propõe na sua Logyca $\left(f^{\circ} 2 v a\right)^{5}$ uma distinção entre duas operações do intelecto: a concepção de uma coisa por relação a uma propriedade (credulitas) e a mera concepção da coisa (intellectio), esta última retomada na sua Metafísica como imaginatio. Ora, é precisamente com essa distinção, que desempenha um papel fundamental na determinação das noções primitivas da metafísica aviceniana (STORCK, 2005), que Algazel inicia sua Lógica. A imaginatio seria a apreensão das noções como ens e res e ocorreria diretamente, ou seja, sem a necessidade de investigação. Já a apreensão das noções que exigem investigação, como o conhecimento da alma e das coisas cujas essências são ocultas, seria a credulitas. ${ }^{6} \mathrm{Na}$ Metafísica, ele retoma o ponto retirando como conclusão que a existência é concebida pelo intelecto por meio de uma primeira concepção, independentemente da investigação de sua definição ou descrição?

\footnotetext{
${ }^{2}$ Encontraremos um panorama das discussões acerca do conhecimento que os latinos possuíam das verdadeiras intenções de Algazel na introdução à Lógica (LOHR, 1965). Para as traduções a partir do árabe, consultamos ALGAZEL, 1963 e ALGAZEL, 1997. A Introdução latina do Maqâsid foi publicada por Salman, 1935-1936. Consulte-se ainda D’Alverny 1994 e, mais recentemente, MINNENA, 2014.

${ }^{3}$ Ao criticar Avicena, Algazel baseou-se no Dânèsh-Nâma. Quando necessário, faremos referência à tradução francesa dessa obra (AVICENA, 1986). Veja-se ainda FRANK, 1987-1989.

${ }^{4}$ Citadas, respectivamente, a partir das edições de LOHR, 1964 e ALGAZEL, 1933. Consulte-se ainda ALGAZEL, 1506.

${ }^{5}$ Por limitações ligadas ao COVID-19, não nos foi possível utilizar AVICENA, 2018.

${ }^{6}$ ALGAZEL, Logica, p. 24022-27: "Amplius, imaginatio et credulitas unaquaeque dividitur in id quod primum apprehenditur per se sine inquisitione et excogitatione, et in id quod non apprehenditur sine inquisitione. Quod autem imaginatur statim sine inquisitione est sicut 'ens' et 'res' et similia. Quod vero non imaginatur sine inquisitione est sicut cognitio spiritus et angeli et imaginatio rerum quarum essentiae sunt occultae."

${ }^{7}$ ALGAZEL, Metafísica, p. 6 4-6: "Constat ergo quod inmaginatio (sic) de esse concipitur in intellectu prima concepcione non per inquisicionem sue diffinicionis, vel descripcionis.” Note-se que, para a Lógica de Algazel, a noção primitiva é o ens, ao que passo que a Metafísica emprega tanto ens quanto esse, o que tornará difícil a distinção entre as noções de ser e existência.
} 
É necessário, no entanto, fazer aqui uma observação de vocabulário. A tradução latina de Avicena utiliza neste contexto a expressão "prima impressione". No entanto, ao optar pelo par "sine inquisitione" e "prima conceptione", a tradução latina de Algazel sublinha o fato de a ordem em questão ser a da justificação das noções e não a de sua origem sensível. A tese, é bem verdade, encontra-se já em Avicena, mas é aqui reforçada por uma explicação que explora melhor as ligações entre a caracterização puramente lógica de uma noção e a determinação da sua origem: é porque as noções são logicamente primitivas, no sentido de serem irredutíveis e indefiníveis, que são as primeiras a serem apreendidas pelo intelecto humano. $\mathrm{O}$ texto de Algazel é, deste ponto de vista, fiel às intenções de Avicena.

Note-se ainda que os latinos estavam bastante atentos a esta nuance entre as duas ordens, como podemos constatar em alguns mestres do século XIII. A título de exemplo, mencionemos primeiramente Filipe, o Chanceler, que, após ter classificado o ens entre as noções as mais comuns, ${ }^{8}$ afirma explicitamente o caráter não analisável desta noção como revelador de sua primazia. ${ }^{9}$ Encontraremos o mesmo tipo de argumentação na Summa Theologica de Alexandre de Hales, o qual afirma explicitamente que o ens é o primeiro inteligível e que as suas determinações são as primeiras impressões, ou seja, são aquelas que não podem ser conhecidas na base de qualquer outra noção. ${ }^{10}$ Também Alberto Magno é categórico a esse respeito: a noção de ens não pode ser reduzida a outra que lhe é prévia e o vocabulário do mestre de Colônia coincide como o de Algazel. ${ }^{11}$

Dito isso, seria precipitado concluir da aceitação do caráter primitivo da noção de ens, sublinhado por Avicena e retomado nas traduções de Algazel, que os latinos teriam endossado todas as consequências admitidas pelo filósofo persa. Como bem demonstrou Aertsen, os autores e textos citados devem antes ser considerados no contexto do desenvolvimento da teoria medieval dos transcendentais. Em particular para os nossos propósitos posteriores, convém salientar que a afirmação do caráter primitivo dos transcendentais não implica a aceitação da tese da acidentalidade da existência. A questão que se coloca é, então, a de saber como os autores latinos interpretaram a posição de Avicena sobre o assunto. Para abordar esse problema, assumiremos como aceitas as relações semânticas entre os termos primitivos da metafísica, tal como transmitidas pelo Liber de Philosophia Prima (AVICENA, 1977-1983), e procuraremos determinar o papel desempenhado pelas obras de Algazel na transmissão dessas teses. Dito de modo mais preciso, admitiremos a tese segundo a qual a caracterização semântica de termos primitivos se situa no cruzamento de duas disciplinas (metafísica e lógica), o que pode ser constatado na forma como ambas as disciplinas abordam os universais. Procuraremos, então, analisar as traduções latinas de Algazel e mostrar como as relações semânticas entre universais, ou seja, as relações entre gêneros e espécies (ou, para falar mais amplamente, as relações de significação entre quaisquer dois termos) vinculam-se à tese aviceniana acerca da acidentalidade da existência. Para tanto, o presente artigo dividir-se-á em duas partes. Na primeira, defenderemos que a Lógica de Algazel oferece uma caracterização da distinção entre essência e existência

${ }^{8}$ FILIPE, O CHANCELER, Summa de Bono, p. 4 43-45: "Communissima autem hec sunt: ens, unum, verum, bonum (...). Ens enim communiter modo dicitur de omnibus, modo appropriatur." Sobre os textos aqui citados, consulte-se AERTSEN, 1996, especialmente o primeiro capítulo.

${ }^{9}$ FILIPE, O CHANCELER, Summa de Bono, apud AERTSEN, 1996, p. 28: "ens et unum et verum et bonum sunt prima (...). Prime intentiones simplices dicuntur, quia non est ante ipsas in que fiat resolutio. Ante prima non est quod in eorum veniat diffinitionem.".

${ }^{10}$ ALEXANDRE DE HALES, Summa Theologica I, ed. Coll. S. Bonaventura, Quaracchi, 1924, p. 113: “Dicendum quod sit 'ens' primum intelligibile, eius intentio apud intellectum est nota; primae ergo determinationes entis sunt primae impressiones apud intellectum: eae sunt unum, verum, bonum, sicut patebit; non poterunt ergo habere aliqua priora specialiter ad sui notificationem." Cf. Aertsen, p. 40-48.

${ }^{11}$ ALBERTO MAGNO, Super de divinis nominibus, apud AERTSEN, 1996, p. 60-61: "Et dicit theologicam ad differentiam philosophici negotii de ente, cuius intentio est determinare de ente, in quo stat resolutio intellectus sicut in primam conceptionem, assignando passiones et partes eius." 
em termos puramente lógicos ao passo que, na segunda, perguntaremos se a distinção recebe, na Metafísica, uma interpretação ontológica e se ela implica a distinção real entre essência e existência.

\section{2) A tese lógica da acidentalidade da existência}

A Lógica de Algazel considera a distinção entre o universal e o particular como uma das divisões da dictio, ou seja, como uma das divisões dos elementos significativos do discurso humano. Nesse contexto, define o singular como a dictio cuja significação proíbe que ela seja atribuída (participari) a muitos, como ocorre nas expressões "este cavalo" ou "esta árvore". Já o universal é definido, por sua vez, como aquela expressão cuja significação não proíbe que seja atribuída a muitos, como "árvore" e "cavalo". ${ }^{12}$ Note-se que o significado de uma dictio não se explica pela existência das seus referentes, mas pela relação de participação e em função de um conceito modal, a noção de possibilidade. Como atesta a distinção entre 'sol' e 'este sol', não é o número atual de referentes que torna a dictio universal ou singular, mas a possibilidade ou impossibilidade da existência de uma pluralidade de referentes. A extensão de uma dictio, ou seja, o conjunto das suas possíveis referências, é determinada em relação ao seu significado e não em relação ao número de seus referentes. Assim, diz-se que uma dictio é singular se o número de referentes não puder ser superior a um e universal se for possível que o número de referentes seja superior a um. Note-se ainda que, contrariamente ao que ocorre em Avicena, a Lógica de Algazel não se coloca explicitamente o problema das classes vazias (STORCK, 2008); afirma simplesmente que uma noção singular tem um número de referentes que é, no máximo, igual a um. Deixa, contudo, intocada a possibilidade de não existirem atualmente referentes. Como compreender esta lacuna? Existem duas possibilidades: ou a lógica pressupõe necessariamente a existência de referentes para os termos definidos, caso em que o número mínimo de referentes é sempre igual a um para termos singulares e sempre superior a um para termos universais; ou a existência de referentes não é uma das condições da significação. Como veremos, uma das consequências da tese da acidentalidade da existência é precisamente o fato de o significado de uma dictio (e, portanto, a sua singularidade ou universalidade) não depender da existência de referentes. A apresentação da dictio faz jus, portanto, à caracterização lógica, na medida em que constitui uma classificação que abstrai da existência real de objetos, considerando exclusivamente o significado dos termos. Além disso, esta classificação segue o espírito da lógica de Avicena, a qual considera termos singulares apenas em relação aos seus significados. ${ }^{13}$ Note-se, no entanto, que a distinção entre existência real e existência mental, central na maneira como Avicenna concebe sua teoria, não é exposta de uma forma sistemática por Algazel.

O segundo elemento de caracterização da dictio universal presente na Lógica de Algazel reside na distinção entre a predicação essencial e a acidental. Frases como "este ser humano é animal" e "este ser humano é branco" são consideradas, respectivamente, como essenciais e acidentais devido não somente a empregarem termos universais, mas em virtude do tipo de propriedade que os termos exprimem. São três as características da predicação essencial:

\footnotetext{
${ }^{12}$ ALGAZEL, Logica, p. 24437-24547: Divisio tertia est quod dictio dividitur in singulare et universale. (1) Singulare est, cuius significatio prohibet illud a multis participari, sicut 'hic Petrus', 'hic equus', 'haec arbor'. (2) Universale vero est, cuius significatio non prohibet illud a multis participari, sicut hoc quod dicitur: 'arbor,' 'equus,' 'homo'. Quamvis enim in mundo non sit nisi unus equus, tamen 'equus' universale est. Possibile est enim in potentia multa participare eo, quamvis hoc non sit in effectu. Quod non fit singulare, nisi dicatur: 'hic equus'. Quapropter cum dixeris 'sol', universale est. Si enim poneretur multos esse soles, tamen sub hoc nomine concluderentur omnes. Quod est contrarium huius dictionis quae est 'hic sol'. A distinção encontra-se em Avicena, Logyca, fo $3 \mathrm{vb}$.

${ }^{13}$ AVICENA, Logyca, fo 3ra: "Similiter est in doctrina logyca: non enim considerat incomplexa harum rerum secundum quod sunt alicuius duorum modorum dictorum esse: secundum quod est in his sensibilibus: aut in intellectu: nec ut est in essentia harum rerum ex hoc quod sunt essentie: sed secundum quod sunt predicata vel subiecta: et universalia aut particularia."
} 
1. Uma predicação é essencial se não for possível imaginar ou conceber o sujeito como não possuindo a propriedade atribuída pelo predicado, sendo o exemplo clássico a proposição: o ser humano é um animal; ${ }^{14}$

Na atribuição do predicado "animal" ao sujeito "ser humano", o predicado é constitutivo do sujeito, no sentido de que o sujeito não pode existir sem a propriedade em questão. ${ }^{15} \mathrm{Tem}$-se, assim, uma correlação entre a necessidade lógica da predicação e a necessidade ontológica de constituição dos objetos. No entanto, deve-se salientar que esta correlação é vista, no escopo da lógica, como uma consequência e não como um ponto de partida. Aos olhos de Algazel e do filósofo cuja teoria ele resume, é perfeitamente possível caracterizar a necessidade lógica de acordo com o significado dos termos e, posteriormente, admitir a necessidade ontológica como uma de suas consequências. A existência real de um objeto $S$ que possua a propriedade constitutiva P não é condição necessária para a verdade da predicação essencial "S é P", e isso por uma razão ligada à maneira como o universal foi introduzido. Dado que o significado de uma dictio universal é independente da existência de seus referentes, então todas as relações lógicas que decorrem da significação da dictio são também independentes da existência dos referentes. O ponto é clarificado através das seguintes definições:

(i) "P" é um predicado universal se, e apenas se, a possibilidade de uma pluralidade de objetos que possuam P não for contraditória;

(ii) "P" é essencialmente baseado em "S" se, e apenas se, a hipótese de objetos que são "S" e que não são "P" for contraditória.

A alínea (ii) afirma ser impossível que algo seja $S$ e não $P$, mas nada diz sobre a existência de objetos que satisfaçam S. Para usar o vocabulário de Algazel, não podemos imaginar o que é um ser humano sem o imaginarmos como animal. Por outro lado, podemos imaginar o que é um ser humano, independentemente de imaginar a existência de seres humanos. ${ }^{16}$ Em suma, as regras (i) e (ii) permanecem válidas mesmo no caso de não apresentarem referentes reais, uma conclusão que Algazel retira explicitamente ao afirmar a acidentalidade da existência. ${ }^{17}$

2. A segunda característica é:O essencial é ordenado: as predicações essenciais superiores precedem as essenciais inferiores; ${ }^{18}$

${ }^{14}$ ALGAZEL, Logica, p. 247 15-19: "cum intellexeris essentiale et id cui est essentiale, non possis imaginari subiectum vel intelligere, nisi intelligas essentiale existere in eo; nec possit ullo modo subiectum intelligi sine illo. Cum enim intelligis, quid est homo et quid est animal, non potes intelligere hominem sine intellectu animalis.'

${ }^{15}$ AVICENA esclarece este ponto ao afirmar que a distinção entre os dois tipos de predicados (essenciais e acidentais) deve reproduzir a distinção entre dois tipos de propriedades (constitutivas e não constitutivas). Assim, um predicado $\mathrm{P}$ é essencial se, e apenas se, significar uma propriedade $Q$, cuja eliminação implica a destruição do objeto que possui Q. Por outro lado, um $P$ é acidental se, e apenas se, significar uma propriedade $Q$ cuja eliminação não implique a destruição do objeto que possui $Q$. AVICENA, Logyca, f 4rb: "Patet igitur diuersitas que est inter comparationem animalis et rationalis: et etiam hominis ad singularia: et inter comparationem accidentium ad ista: primis enim destructis debent destrui singularia: sed propter ipsam destructionem secundorum non deberet destrui singulare. Ex his autem sunt quedam que destruuntur: et quedam que impossibile est destrui: nisi destruantur singulare. Et quoniam ita est in re; tunc substantiale erit continens quicquid significat esse rei."

${ }^{16}$ ALGAZEL, Logica, p. 247 18-19: "non potes intelligere hominem sine intellectu animalis." ALGAZEL, Logica, p. 247 26-27: "cum intelligis, quid est homo, non est necesse te inteligere eum esse."

${ }^{17}$ ALGAZEL, Logica, p. 247 30-32: "Pone ergo aliud exemplum - sicut de phoenice vel de aliquo alio extraneo - et ibi manifestabitur tibi, quia esse accidentale est omnibus quae sunt."

${ }^{18}$ ALGAZEL, Logica, p. 24734-37: "Secundum est, ut possit intelligi universale necessario esse prius, posterius vero particulare contendum sub eo, vel in esse vel in intellectu. Sicut necesse est, ut prius sit animal, deinde equus vel homo; et necesse est prius esse numerum, deinde quattuor." 
O ponto de partida aqui é a hierarquia entre os predicados mais e menos gerais, tal como os encontramos, por exemplo, na árvore de Porfírio. Sublinhemos apenas que, segundo Algazel, a ordem lógica de descida do mais alto para o mais baixo grau é suposta reproduzir tanto a ordem epistemológica de intelecção quanto a ordem ontológica de constituição dos seres. ${ }^{19}$ Esse princípio exprime, em última instância, o fato de a noção prima intelligibile ser também a noção mais geral do ponto de vista lógico e ontológico. Leva também à conclusão de que o processo de intelecção deve seguir a mesma ordem.

\section{A terceira característica é:}

3. O essencial é absoluto: a predicação essencial não pode estabelecer condições (non positivum); ${ }^{20}$

Esta característica é mera consequência da primeira. Como é impossível conceber uma coisa independentemente das suas características essenciais, hipóteses como: "Suponha que o ser humano seja um animal” não são verdadeiras hipóteses, uma vez que, se não for possível presumir que uma coisa não é $x$, então não faz sentido dizer que presumimos que é x. ${ }^{21}$ Algazel conclui que todas as suposições pertencem ao domínio do acidental e o exemplo que dá ("Suponha a existência de seres humanos") é uma caracterização da existência como acidental. Em suma, a Lógica de Algazel explica predicações essenciais do tipo: "P = 'o ser humano é um animal", de acordo com as seguintes características:

a) P é verdadeira;

b) P não supõe a verdade da proposição "existem seres humanos";

c) P não implica a proposição "existem seres humanos";

O vínculo entre a predicação essencial e as modalidades torna-se assim mais claro. Com efeito, dizer que a ligação entre o sujeito e o predicado é essencial ou acidental equivale a dizer que essa ligação é necessária quando o predicado é essencial (ou seja, o sujeito possui necessariamente o atributo em questão) ou possível quando o predicado é acidental (ou seja, o sujeito pode ou não possuir o atributo em questão). Resta um terceiro caso, o da impossibilidade, que nada mais é do que uma predicação contrária à essência do sujeito. Por conseguinte, a divisão das proposições modais passa a ser vista como expressando o tipo de vínculo que um sujeito pode ter com o predicado que lhe é atribuído. Se o sujeito não pode não possuir o predicado, a predicação é necessária; se o sujeito não pode possuí-lo, a predicação é impossível e, se o sujeito pode ou não possuir o predicado, a predicação é acidental..$^{22}$

Podemos então acrescentar uma quarta característica à lista acima:

4. O essencial é necesário

\footnotetext{
${ }^{19}$ ALGAZEL, Logica, p. 248 46-48: "Sed dicetur, quod necesse est prius esse hominem ad hoc, ut sit risibile. Ex hac autem prioritate non intelligitur ordo temporalis, sed ordo intellectualis, quamvis sint paria in tempore."

${ }^{20}$ ALGAZEL, Logica, p. 248 49-51: "Tertium est, quia non est possibile essentiale esse positivum. Non enim potest dici: 'Ponamus hominem esse animal, et nigredinem esse colorem, et quattuor esse numerum."

${ }^{21}$ ALGAZEL, Logica, p. 248 51-55: “Quoniam homo essentialiter est animal, non propter positionem alicuius. Si enim propter positionem alicuius homo esset animal, tunc possibile esset imaginari nos posse ponere illum hominem et non animal. Hoc autem non est possibile aestimari."

${ }^{22}$ ALGAZEL, Logica, p. 255125-256129: “( ... ) propositio secundum intentionem comparationis sive habitudinis praedicati ad subiectum dividitur in possibile, ut: 'Homo est scriptor', et 'Homo non est scriptor'; et in impossibile, ut: 'Homo est lapis', et 'Homo non est animal'; et in necessarium, ut: 'Homo est animal', 'Homo non est lapis'.
} 
A importância de deixar claro o ponto advém do tipo de necessidade exigida pelo conhecimento científico. De acordo com um princípio aristotélico amplamente aceito durante a Idade Média, a ciência é sempre sobre o que é necessário. Mas qual seria o tipo de necessidade em questão? Evidentemente, a necessidade temporal não é suficiente para explicar esse princípio, pois, se assim o fosse, mesmo proposições singulares em matéria passada seriam científicas. Os medievais excluíam, no entanto, tais proposições do domínio científico. ${ }^{23}$ Isto significa então que a necessidade própria da ciência não é exclusivamente da ordem temporal, ou melhor, não é a necessidade dependente da existência temporal de coisas singulares. Qual seria, então, o tipo de necessidade exigida pela ciência? A concepção das modalidades introduzidas pela Lógica de Algazel permite distinguir entre a necessidade temporal e a necessidade essencial. Por um lado, as proposições singulares dotadas de necessidade temporal serão sempre vistas como acidentais e, portanto, como meramente possíveis, sendo excluídas, por conseguinte, do campo do saber científico. Por outro lado, a ligação essencial entre o sujeito e o predicado oferece uma forma de compreender por que certas proposições são verdadeiras, universais e necessárias de uma forma absolutamente não temporal.

Sem entrar nos pormenores da teoria da ciência difundida por Algazel, sublinhemos apenas uma consequência das teses acima defendidas. Se somente há ciência do necessário e se somente o essencial é necessário, então somente há ciência do essencial. Contudo, uma vez que proposições essenciais são verdadeiras mesmo na ausência de objetos, poder-se-ia concluir que a ciência pode prescindir da existência de objetos. Sabemos que alguns latinos adotaram este tipo de solução. Seria esse o caso da Algazel? Uma leitura dos parágrafos finais da Lógica mostra que ele estava plenamente consciente da dificuldade e propôs uma caracterização mais precisa da noção de predicação essencial para explicar as verdades científicas. Algazel mantém sempre como ideia básica que a ligação entre o sujeito e o predicado pode ser possível ou necessária e que o último é a marca da predicação essencial. No entanto, acrescenta duas formas de conceber o elo essencial: 1) o predicado pertence à definição do sujeito, como em "os seres humanos são animais", em que o predicado nada informa que já não estivesse informado no sujeito; 2) o sujeito pertence à definição do predicado, mas não o inverso, como no exemplo clássico "nariz adunco". ${ }^{24} \mathrm{~A}$ investigação científica está mais interessada na segunda, sendo a primeira um pressuposto deste tipo de abordagem. ${ }^{25}$

Após tratar da predicação essencial, a Lógica de Algazel passa a examinar a predicação acidental. No entanto, caso buscássemos nesse momento a caracterização precisa da tese da acidentalidade da existência, ficaríamos decepcionados com o silêncio de Algazel e isso a despeito da afirmação explícita de que a existência é um acidente. ${ }^{26} \mathrm{Com}$ efeito, as duas divisões do acidental, comitans separabile et inseparabile, por um lado, e absolutum et proprium, por outro, não trazem qualquer precisão à noção de existência. ${ }^{27}$ Mesmo assim, esse silêncio é eloquente. A existência não é um predicado acidental como os demais. Podemos mesmo dizer que a Lógica de Algazel revela o dilema que envolve a noção aviceniana de existência. Por um lado, a existência não pode ser um predicado essencial, porque seria constitutiva de objetos e, portanto,

${ }^{23}$ ALGAZEL, Logica, p. 286 160-163: "Necessariae vero sunt ut animal homini, non ut scriptor homini. Haec enim conditio est, cum quaeritur de ea conclusio necessaria. Cum enim propositio non fuerit necessaria, sapiens non debet necessario credere conclusionem."

${ }^{24}$ ALGAZEL, Logica, p. 287 194-201: “(a) Uno, ut praedicatum intret in definitione subiecti, ut animal homini, quoniam ipsum essentialiter inest homini, et intrat in definitione eius. Sensus enim huius, quod dicitur homo nihil aliud est quam animal tale. (b) Secundo, ut subiectus intret in definitione praedicati, non e converso. Sicut simus nasi, et rectitudo lineae. Intellectus enim simi nihil aliud est quam habens nasum huiusmodi. Nasus igitur est in definitione simi sine dubio."

${ }^{25}$ ALGAZEL, Logica, p. 287 202-205: "Essentiale autem secundum primum modum supervacuum est esse praedicatum in quaestionibus, quae quaeruntur in scientis. Subiectum enim non cognoscitur nisi per praedicatum. Unde prior est cognitio praedicati cognitione subiecti."

${ }^{26}$ ALGAZEL, Logica, p. 249 105: "Esse vero accidentale est, non essentiale."

${ }^{27}$ Veja-se: AVICENA, Logyca, fo 9v e AVICENA, 1951, p. 101 e o comentário de Goichon (p. 101, n. 3) que encontra a mesma imprecisão em Avicena. 
de suas essências; por outro, também não pode ser um predicado classificado em uma das nove categorias acidentais. Isso significa que, nos limites da Lógica de Algazel, a existência não é um predicado, ou pelo menos não é um predicado como os demais, uma vez que não pode ser classificada como uma predicação essencial ou em uma das nove categorias acidentais.

Sejamos mais explícitos. Algazel vê muito claramente que a existência não é um predicado categórico. Segundo ele, trata-se mais de um predicado transcategorial, no sentido de um predicado atribuível tanto às substâncias como aos acidentes. Pela mesma razão, a existência não pode ser aquilo a que Aristóteles chamou de predicados unívocos ou equívocos. A Lógica de Algazel propõe, então, como forma intermédia a noção de convenientia, que será retomada pelos latinos sob a forma da analogia. ${ }^{28}$

Convenientia são intermediários entre termos unívocos e equívocos, sendo o exemplo principal justamente a noção de ens, que é atribuída tanto a termos na categoria da substância quanto a termos em todas as categorias acidentais. A tradução latina de Algazel precisa então a particularidade desse tipo de predicação por meio do célebre sintagma secundum prius et posterius. ${ }^{29}$ Após, ele retoma a discussão ao determinar a hierarquia de predicados que caracteriza a árvore de Porfírio e argumenta que ens não pode ser um gênero superior à substância porque é acidental e que as predicações nessa categoria são todas essenciais. ${ }^{30}$ Resulta daí que o grau máximo na série de predicações essenciais, o genus generalissimum, é a substância. Quanto à especie specialissima, ou seja, o grau mínimo na série de predicados essenciais, Algazel argumenta que deve ser uma noção cuja divisão é acidental. Com efeito, diz-se que uma espécie (v. g., animal) é superior a duas outras (ser humano e cavalo) se se distinguirem por uma característica essencial. Assim, caso haja uma espécie que não possa ser dividida por meio de predicações essenciais, ela será a espécie mais baixa nessa série hierárquica. E como ela somente poderá ser dividida por características acidentais, a relação muda de natureza. Os membros da espécie serão chamados de "indivíduos" e a espécie sobre a qual se opera a divisão é então denominada especie especialissima. ${ }^{31}$

Ocorre, nesse contexto, uma dupla utilização da noção de acidente, pois a noção serve tanto para explicar por que o ens não é um gênero quanto por que indivíduos não são espécies. Essas são, no entanto, obviamente duas relações distintas. Vejamos brevemente as séries de gêneros e espécies que compõem a categoria da substância. Essa série pode ser vista em dois sentidos: ascendente ou descendente. No primeiro, os indivíduos ou espécies inferiores são considerados como acidentes de espécies ou gêneros superiores. Assim, proposições como:

1) Os seres humanos são Maria, José, Pedro, etc.;

\footnotetext{
${ }^{28}$ Sobre esse clássico tema, citemos apenas: ASHWORTH, 2008 e LIBERA, 1989.

${ }^{29}$ ALGAZEL, Logica, p. 246 85-92: “(5) Convenientia sunt media inter univoca et aequivoca, ut 'ens', quod dicitur de substantia et accidente. Non enim est sicut haec dictio 'canis'. Ea enim quae appellantur 'canis' non conveniunt in aliqua significatione canis. Esse vero convenit substantiae et accidenti. Nec sunt sicut univoca. Animalitas enim aeque convenit equo et homini indifferenter et eodem modo. Esse vero prius habet substantia; deinde accidens, mediante alio. Ergo est eis esse secundum prius et posterius. Hoc dicitur ambiguum, eo quod aptatur ad hoc et ad hoc."

${ }^{30}$ ALGAZEL, Logica, p. 249 105-106: "Esse vero accidentale est, non essentiale. Genus autem intelligitur quod est essentiale communius."

${ }^{31}$ ALGAZEL, Logica, p. 250 112-123: "Homo vero dicitur species specialissima, eo quod non dividitur nisi in ea tantum quae sunt accidentalia, ut in puerum et iuvenem, longum et brevem, sapientem et insapientem. Haec autem accidentalia sunt, non essentialia. Nam homo differt ab equo essentialiter, et nigredo ab albedine essentialiter. Haec autem nigredo non differt ab illa nigredine natura et essentia. Si autem haec nigredo in incausto, illa autem in corvo; sed illa, quantum ad corvum, accidentalis est. Petrus vero non differt a Iohanne in humanitate vel in aliquo essentiali, sed in hoc, quod est filius alterius singularis, vel est alterius terrae, vel alterius coloris, vel alterius quantitatis, vel alterius moris, vel alterius vitii. Haec autem omnia accidentalia sunt homini, sicut praedicatum est in assignatione accidentalis."
} 
2) Os animais são seres humanos, cavalos, cães, etc.;

são acidentais porque, para uma natureza qualquer, o fato de ela estar exemplificada em tal ou tal pessoa, ou em tal ou tal gênero, é algo totalmente acidental. ${ }^{32}$ Por outro lado, se considerarmos agora os mesmos elementos, mas desta vez do ponto de vista da ordem descendente, notaremos que as espécies e os gêneros superiores são essenciais para os indivíduos e espécies inferiores. Por exemplo, as proposições:

3) Maria é um ser humano;

4) Os seres humanos são animais;

são essenciais e necessárias. Isso explica mais claramente por que o grau superior da série ascendente não é o ens. Essa noção não segue as regras que acabamos de revisar. Não pode ser atribuída de forma unívoca às demais noções. De acordo com o famoso princípio aristotélico, já citado por Algazel e que está na origem deste problema, a divisão do ens nas dez categorias não é uma divisão essencial, mas é secundum prius et posterius.

Em resumo, podemos concluir que a Lógica de Algazel oferece uma teoria de existência bastante simples. Proposições como "S existe" não são necessárias, uma vez que a existência é extrínseca a qualquer essência. E, como em sentido mais amplo, toda a predicação não essencial é acidental, a existência é apresentada como um acidente. Passaremos a chamar a esta forma de caracterização da existência "a versão lógica da existência como um acidente". Essa caracterização deixa, contudo, alguns pontos sem resolver e exigirá complementações oferecidas pela Metafísica.

\section{3) A tese metafísica da acidentalidade da existência}

Por razões atinentes à divisão das disciplinas científicas, a Metafísica de Algazel retoma diversos pontos tratados na Lógica, de modo que encontramos ali um aprofundamento da tese lógica da existência considerada como um acidente. ${ }^{33} \mathrm{Em}$ termos gerais, a metafísica fornece uma resposta à questão de saber quais são as repercussões ontológicas das distinções apresentadas na lógica. Assim, perguntas típicas da metafísica são, para retomar uma expressão de Forest (1956): quais seriam, para a estrutura metafísica do concreto, as consequências das distinções lógicas? Qual seria a contrapartida metafísica da distinção entre essência e existência? A distinção lógica implicaria separação ontológica? Embora o texto de Algazel seja obscuro em algumas passagens, pretenderemos mostrar que a caracterização lógica da existência como um acidente não implica a dita distinção real. Para tanto, analisaremos algumas passagens centrais da Metafísica de Algazel e discutiremos o significado ontológico da dita distinção.

A Metafísica de Algazel começa por enumerar as principais divisões do esse, a primeira das quais diz respeito à substância e ao acidente. ${ }^{34}$ Afastemos, desde já, certa ambiguidade do termo "primeiro" a qual implicaria uma primazia ontológica, ou mesmo uma divisão exaustiva do ser, o que não é obviamente o caso para Algazel. Essa primeira divisão é apenas uma subdivisão válida exclusivamente para o ser finito, não se aplicando ao ser infinito, ou seja, a Deus. Trata-se aqui de uma consequência direta de uma

\footnotetext{
${ }^{32}$ Notemos que, segundo Algazel, dois indivíduos distintos que compartilham uma mesma espécie não podem ser distintos em razão de suas características específicas. ALGAZEL, Logica p. 250 118-123: "Petrus vero non differt a Iohanne in humanitate vel in aliquo essentiali, sed in hoc, quod est filius alterius singularis, vel est alterius terrae, vel alterius coloris, vel alterius quantitatis, vel alterius moris, vel alterius vitii. Haec autem omnia accidentalia sunt homini, sicut praedictum est in assignatione accidentalis."

${ }^{33}$ E nisso Algazel parece seguir uma lição de Avicena. Cf. AVICENA, Logyca, 3rb: "scies quod tractatus de scientia subiecti est unius doctrine: et tractatus de eius accidentibus est alterius doctrine: et similiter debes scire de dispositione logyce."

${ }^{34}$ ALGAZEL, Metaphysica, p. $5^{13-14}$ : "Prima divisio esse est in substantiam et accidens."
} 
importante tese metafísica e que se reflete no movimento argumentativo da Metafísica de Algazel, a saber: as distinções válidas para o domínio finito não são válidas para o domínio infinito. Assim, ao contrário da Metafísica da Shifâ', onde a distinção entre o ser necessário e os seres possíveis é feita no primeiro capítulo, ${ }^{35}$ na Metafísica do Dânèsh-Nâna, obra que serve de referência a Algazel, a investigação do modo de ser das substâncias finitas precede a da existência e das propriedades divinas. ${ }^{36}$

Conforme já afirmamos anteriormente, a Metafísica de Algazel considera a apreensão do ser (esse) como uma primeira concepção (prima conceptione), sem que seja envolvida qualquer investigação baseada em uma definição ou descrição. ${ }^{37} \mathrm{O}$ ser não possui definição pois, estritamente falando, definições envolvem gênero e diferença específica, mas isso não vale para o ser, pois não há gênero superior ao ser ao qual possa aplicar-se uma diferença. Quanto às descrições, elas somente fazem sentido na medida em que permitem apreender algo menos manifesto partindo-se do que é mais manifesto. Todavia, como nada é mais manifesto que o ser, esse procedimento não pode ter lugar na apreensão do ser.

Dito isto, a Metafísica de Algazel apresenta uma interpretação das distinções do ser bastante próxima da professada por Aristóteles. Partindo dos tipos de ligações possíveis entre o sujeito e as suas propriedades, Algazel fornece uma caracterização das propriedades acidentais de acordo com os seus modos de existência. Ou seja, o ser divide-se em substância, aquilo que existe por si ou que não necessita de algo outro para subsistir, e acidentes, aquilo que necessita de algo outro em que possa subsistir. ${ }^{38}$

Quanto à substância, a Metafísica de Algazel parece retomar uma lição do Livro $Z$ da Metafísica de Aristóteles que considerava como substância quer a forma, quer a matéria ou o composto de ambos. Algazel acrescenta um quarto sentido e depois obtém os quatro tipos seguintes:

1) A forma: as propriedades constitutivas de um sujeito, nomeadamente aquelas cuja supressão é, ipso facto, a supressão do sujeito;

2) O substrato: o sujeito que serve de substrato para a forma;

3) O composto: o objeto físico resultante da união da matéria e da forma, ou seja, os corpos sensíveis;

4) As inteligências. ${ }^{39}$

Já as propriedades acidentais são aquelas cuja existência depende da existência prévia de um sujeito que pode, por sua vez, existir independentemente dessas propriedades e estão divididas, tal como em Aristóteles, em nove tipos ou categorias que formam dois grupos principais:

\footnotetext{
${ }^{35}$ Cf. AVICENA, 1977-1983, p. 43-48.

${ }^{36}$ Cf. ALGAZEL, Metaphysica, p. 46-51.

${ }^{37}$ ALGAZEL, Metaphysica, p. 515-19: “(...) intellectus apprehendit esse secundum modum imaginacionis sine dubio, nec eget ad apprehendendum, diffinicione, vel discripcione; esse enim non habet diffinicionem, nec descriptionem.”

${ }^{38}$ ALGAZEL, Metaphysica, p. 6 7-9: "dividitur ens, in id quod eget subiecto in quo subsistit ut accidencia, et in id quod non eget subiecto."

${ }^{39}$ ALGAZEL, Metaphysica, p. 7 12-14: “(...) dividitur ergo substancia in quatuor species que sunt hyle, forma, corpus, et intelligencia separata per se existens." Entre os quatro tipos citados, a única cuja existência não é problemática são os corpos. ALGAZEL, Metaphysica, p. 7 22-23: "De intelligencia enim, et de hyle, et de forma, probacio queritur sine dubio." Não reproduziremos aqui essas provas. Salientemos apenas o uso estrito da palavra "forma" como significando sempre a forma por relação à quididade, o que é, diga-se de passagem, uma lição aviceniana. Cf. AVICENA, 1977-1983, V, 5, p. 275 65-66: "Forma enim semper est pars quidditatis in compositis."
} 
a) Acidentes cuja essência somente pode ser concebida se também for concebido algo extrínseco à substância. É o caso dos acidentes relacionados com as seguintes categorias: relação, lugar, tempo, situação, ter, ação e paixão;

b) Acidentes cuja concepção depende apenas da substância em si: qualidade e quantidade. ${ }^{40}$

Até o momento, podemos afirmar que, apesar da introdução de algumas teses estranhas ao pensamento de Aristóteles, a Metafísica de Algazel parece estar de acordo com as linhas principais ensinadas pelo Estagirita. A situação muda, contudo, de figura a partir do momento em que a unidade é considerada como um acidente. Com efeito, após recordar a divisão da quantidade em discreta e contínua e após fornecer o número como exemplo do segundo tipo, ${ }^{41}$ Algazel defende que o número é um acidente por ser constituído de repetições da unidade, ela própria um acidente. Algazel fornece então a famosa prova de unidade como um acidente de substância. $O$ argumento parte da constatação de que a unidade pode ser encontrada na água, no ser humano ou em outra substância. No caso da água, é preciso distinguir-se então a forma da água (aqueitas) e sua unidade, ou seja, aquilo que torna a água una e que, se for dividida, haverá duas. Portanto, como unidade e dualidade alternam-se no sujeito água, ambas são acidentes desse sujeito. O que caracteriza a unidade é, portanto, que o sujeito a que ela é atribuída não a possui em sua essência. De fato, isso é comum a todo acidente, ou seja, o fato de ser uma propriedade de algo distinta da essência deste algo. ${ }^{42}$

Estamos frente a um argumento típico relativo à passagem da unidade como acidente lógico para a unidade como acidente ontológico. De fato, a apresentação de uma ligação acidental entre noções como "água" e "unidade" é característica da abordagem lógica: como a noção de unidade é externa à noção de água, a ligação entre as duas noções é acidental. No entanto, o argumento continua no sentido de uma interpretação ontológica dessa ligação, ou seja, uma interpretação em termos de um sujeito de atributos e das suas propriedades. Basta tomar a frase: "a água é o sujeito, enquanto a unidade é um acidente", e lê-la à luz da definição de acidente dada pela Metafísica (ou seja, acidente é o que existe em um sujeito o qual não necessita do acidente para ser constituído ${ }^{43}$ ) para perceber que tudo o que é extrínseco à essência de uma substância lhe pertence como um acidente. Em suma, neste caso, o correlato ontológico da essência seria a substância, ao passo que os correlatos dos acidentes da essência seriam os acidentes da substância. Sendo assim, podemos classificar a unidade na categoria da quantidade, da mesma forma que classificamos o branco na categoria de qualidade. Além disso, em ambos os casos, a presença ou ausência

\footnotetext{
${ }^{40}$ ALGAZEL, Metaphysica, p. 19 16-21: “[accidencia] autem dividuntur in duo, quoniam quedam eorum sunt quorum essencia nullo modo per se potest intelligi, nisi aliquid aliud extrinsecus intelligatur; et quedam eorum sunt que per se intelligi possunt; et hec dividuntur in duas species, quantitatem scilicet et qualitatem."

${ }^{41}$ ALGAZEL, Metaphysica, p. 22 6-9: "Discreta vero quantitas intelligitur numerus qui eciam accidens est; numerus enim provenit ex repeticione unitatum."

${ }^{42}$ ALGAZEL, Metaphysica, p. 22 21-33: "Quod autem unitas sit accidens, sic ostenditur, quoniam unitas vel est in aqua, vel in homine, vel in equo, vel in aliquo aliorum; aqueitas autem aliquid est, et unitas aliquid aliud est, ex quibus fit aqua una que divisa fit duo, sed coniunctum una. Ergo vicissitudinantur dualitas et unitas in ea; aqua igitur subiectum est, sed unitas, et dualitas, accidencia. (...) Igitur quod intelligitur de uno hoc est, secundum quod subiectum sit constitutum in sua essencia, et in suo esse, sine posicione unitatis, quod omnino intellegendum est de accidente."

${ }^{43}$ ALGAZEL, Metaphysica, p. 7 2-3: "intelligitur accidens quod existit in subiecto", a saber: ALGAZEL, Metaphysica, p. 6 10-11: "id quod venit in subiectum, iam constitutum per se sine illo acidente."
} 
da propriedade em questão não altera a natureza da substância. ${ }^{44}$ Logo, para além da apresentação lógica da unidade como um acidente, a Metafísica de Algazel parece professar uma concepção ontológica da unidade como um acidente. Poder-se-ia talvez objetar que a unidade é inseparável da substância (como o próprio Algazel admite, aliás, no caso do ser humano ${ }^{45}$ ) e defender uma interpretação mais fraca de acidente. Tal interpretação basear-se-ia principalmente na ideia de acidente inseparabile estudado na Lógica. Mesmo assim, a conclusão final permaneceria: a unidade é algo que advém ao sujeito já constituído, merecendo assim a qualificação de acidente de substância. ${ }^{46}$

Em um artigo frequentemente citado, Zedler (1976, p. 512) pergunta-se se as críticas de Averróis a Avicena estariam justificadas: "Teria Averróis sido justo com Avicenna? Teria ele razão ao atribuir-lhe a opinião de que a existência é um acidente predicamental, ou seja, 'algo adicional à essência fora da alma', que porque os conceitos de unidade e existência de uma coisa são distintos do nosso conceito da sua essência, portanto unidade e existência são realmente distintas da essência?” A pergunta, assim como a solução proposta, fazem parte de um longo debate envolvendo as posições de Avicena e Averróis e tendem a dizer que, em certo sentido, Averróis teria razão, pois: "o que Avicena apresentou em um plano lógico como uma distinção mental parece efetivamente tornar-se uma "composição entitativa” no seu domínio metafísico." (ZEDLER, 1976, p. 513). A solução do problema estaria na adoção de um princípio caritativo de leitura que permitiria concluir que se Avicena admite (ou deveria admitir) a distinção real como consequência da distinção lógica, então Averróis teria razão em sua crítica, mas Avicena teria também tido razão ao chamar a atenção para o aspecto lógico do problema. Em última instância, aos olhos da intérprete, o problema seria superado pela posição de Tomás de Aquino. Sem discutir as pressuposições desse modo de praticar a história da filosofia, chamemos a atenção para alguns pontos.

Por um lado, a Metafísica de Algazel parece efetivamente endossar as críticas endereçadas por Averróis a Avicena, especialmente quando o Comentador escreve:

[Avicena] errou nesse ponto porque confundiu os acidentes subsequentes à coisa segundo o intelecto com os acidentes subsequentes à mesma coisa segundo o ser. ${ }^{47}$

\footnotetext{
${ }^{44}$ Em certo sentido, o texto de Avicena que serve de base a Algazel não permite a intepretação acima, sobretudo porque a frase "aqua igitur subiectum est, sed unitas, et dualitas, accidentia" não possui equivalente. Dito isso, o texto não é isento de ambiguidades, principalmente no que toca a noção de acidente. Eis a passagem correspondente em sua versão francesa: AVICENA, 1986, p. 153-154: "Nous disons que le nombre est accident parce que le nombre vient de l'unité; et cette unité qui se trouve dans les choses est accident, comme tu dis un «homme» et une «eau». Autres choses sont humanité et aquatilité; autre chose est unité. L'unité est attribut pour l'une et l'autre, extrinsèque à leur réalité essentielle et à leur quiddité. C'est par là qu'une eau devient deux et que deux eaux devienne une, comme tu l'as connu ; mais un homme ne pourrait devenir deux parce que c'est un accident inséparable de lui. Par conséquent l'unité est un état dans un sujet devenu une chose en elle-même. Tout ce qui est ainsi est accident. Donc l'unité est un accident ; [j'entends par unité] cette unité qui se trouve dans une chose comme dans l'eau et dans l'homme. L'unité est son attribut ; le nombre résulte de l'unité ; a fortiori le nombre serait davantage accident, pour ainsi parler."

${ }^{45}$ ALGAZEL, Metaphysica, p. 22 27-30: "Verum est autem quod unus homo non potest fieri duo, quoniam unum inseparabile est ei; hoc autem non aufert ei esse accidens."

${ }^{46}$ A conclusão de Algazel parece ser, então, mais forte do que a de Avicena. Com efeito, o filósofo persa diz simplesmente o seguinte: AVICENA, 1986, p. 154: "Par conséquent, l'unité est un état dans un sujet devenu une chose en elle-même. Tout ce qui est ainsi est un accident. Donc, l'unité est un accident.” Já Algazel afirma: ALGAZEL, Metaphysica, p. 22 30-33: “Igitur quod intelligitur de uno hoc est, secundum quod subiectum sit constitutum in sua essencia, et in suo esse, sine posicione unitatis, quod omnino intellegendum est de accidente."

${ }^{47}$ AVERRÓIS. 1574, fo 360vH: "Erravit [sc. Avicenna] tunc in hoc, quia ipse admiscuit accidentia insequentia rem secundum intellectum cum accidentibus insequentibus ipsam rem secundum esse." Não buscamos reconstruir aqui a totalidade das críticas de Averróis a Avicena. Para uma discussão mais completa do ponto, consulte-se: CRUZ HERNANDEZ, 1997, p. 371-374.
} 
Averróis buscava denunciar uma confusão entre duas ordens de acidentes e, de acordo com o que acabamos de ver, o argumento que Algazel reproduz parece supor a passagem entre as duas ordens. No entanto, no momento de expor a alegada falha de Avicena, Averróis escreve:

$\mathrm{E}$ [Avicena] considerou que o uno é dito univocamente de todos os dez predicamentos e non secundum prius et posterius e que se trata de um número. ${ }^{48}$

No livro destinado à refutação de Algazel, Averróis retoma o mesmo ponto e acusa o seu adversário de obliterar, seguindo Avicena, a distinção entre o ens no sentido de ser verdadeiro e o ens que se divide nas dez categorias. Ainda segundo o Comentador, após terem realizado a confusão, restaria aos dois pensadores um caminho a trilhar: a afirmação do ens como um acidente da quididade, tese que conduziria inexoravelmente à univocidade do ens, pois tratar-se-ia de mesma noção predicada de todas as dez categorias. ${ }^{49}$

Notemos, no entanto, que se por um lado Algazel parece efetivamente endossar as críticas de Averróis, por outro o mesmo Algazel fornece argumentos para mostrar que o Comentador vai mais longe em censurar Avicena por uma posição que não é sua e que seria mesmo contrária aos ensinamentos do filósofo persa. Apesar das imprecisões e incertezas que revela, a Metafísica de Algazel instrui-nos, de forma quase paradoxal, sobre o caráter exagerado das críticas de Averróis. A letra do texto não deixa margem à dúvida: as noções de "ser" e "unidade" não podem ser consideradas unívocas nem equívocas, ${ }^{50}$ mas devem ser classificadas como um intermediário entre essas noções, um intermediário que é referido como ambiguidade. ${ }^{51} \mathrm{O}$ esse aviceniano diz-se primeiramente da substância e depois da qualidade e da quantidade, sendo apenas posteriormente predicado das demais categorias. Portanto, contrariamente ao que afirma Averróis, Algazel ensina-nos explicitamente que o esse aviceniano aplica-se às categorias secundum prius e posterius. ${ }^{52}$

Salientemos, todavia, que nosso objetivo não é o de apresentar um argumento peremptório sobre o caráter infundado das críticas de Averróis a Avicena. Citamos as opiniões do filósofo de Córdoba com o único objetivo de esclarecer as posições defendidas por Avicena e reproduzidas por Algazel. Neste sentido, parece-nos importante insistir em dois pontos. Em primeiro lugar, a tese da univocidade do esse não pode de forma alguma ser atribuída a Avicena sob pena de uma completa desfiguração do seu pensamento. Pelo menos neste ponto, Algazel reproduz corretamente a tese de Avicena. Insistamos, por outro lado, no lugar absolutamente central ocupado por esse problema no pensamento de Avicena. Com efeito, a recusa da univocidade do ser está no centro de seu sistema e constitui um dos pontos de demarcação entre lógica e

${ }^{48}$ AVERRÓIS. 1574, fo 360vH: "et putauit unum dici vniuoce de omnibus decem praedicamentis non secundum prius et posterius, et quod est unum numerale.”

${ }^{49}$ AVERRÓIS. 1961. "Cum autem aliquis dicit quod esse est additum quidditati, et non constituitur eo ens ex se, est sermo fallax nimis, quoniam sequitur ex hoc ut nomen entis significet accidens commune decem praedicamentis extra animam. Et est opinio Avicennae."

${ }^{50}$ ALGAZEL, Metaphysica, p. 24 29-30: "Si autem queritur an esse dicatur de his decem univoce, vel equivoce, respondebimus quod nec univoce nec equivoce."

${ }^{51}$ ALGAZEL, Metaphysica, p. 26 6-10: "Hec igitur decem conveniunt in esse uno modo, et differunt in esse alio modo, et propter hoc sunt media inter equivoca, et univoca, et idcirco nomen huius modi quod est ens, vocatur nomen ambiguum, eo quod aptatur omnibus."

${ }^{52}$ ALGAZEL, Logica, p. 246 88-92: "Esse vero convenit substantiae et accidenti. Nec sunt sicut univoca. Animalitas enim aeque convenit equo et homini indifferenter et eodem modo. Esse vero prius habet substantia; deinde accidens, mediante alio. Ergo est eis esse secundum prius et posterius. Hoc dictum ambiguum, eo quod aptatur ad hoc et ad hoc." Algazel, Metaphysica, p. 2533-2601: "esse vero prius est substancie et deinde quantitati, et qualitati, mediante substancia; ceteris vero predicamentis convenit esse, mediantibus his duobus quantitate, et qualitate; sic ergo accidit eis prius et posterius." $\mathrm{O}$ texto de Avicena seguido por Algazel afirma o seguinte, conforme a sua tradução francesa: AVICENA, 1986, p. 158: "Donc existence s'applique à ces catégories par priorité et postériorité et par degrés de plus ou moins, bien qu'il ait toujours même sens; et c'est ce terme qu’on dénomme équivoque." 
metafísica. Recordemos que um dos problemas apontados pela Lógica de Algazel, que exigeria um exame especificamente metafísico, era precisamente a relação entre o genus generalissimum e o ens. A metafísica teria por função explicar por que o ser é um predicado acidental e, portanto, por que a substância é o gênero supremo. No entanto, se olharmos para as razões apresentadas pela Metaphysica de Algazel, veremos que o argumento gira em torno do caráter primitivo das noções de "esse/ens" e "res" e tem por consequência que o esse não é unívoco nem equívoco.

Comecemos pela crítica à univocidade do esse, a mais simples das duas e que resulta quase que diretamente da natureza indefinível do ser. Com efeito, uma vez que não existe uma noção através da qual o ser possa ser conhecido e definido, ${ }^{53}$ ele não pode ser nem um gênero nem a fortiori o gênero supremo comum a todas as categorias. Assim, o esse não é unívoco. Esse argumento, apresentado aqui em suas linhas gerais, depende da univocidade como característica intrínseca dos predicados categóricos. É então a exclusão do esse do domínio categórico que implica que não se trata de uma noção unívoca.

A crítica à equivocidade do esse é mais complexa. A Metaphysica de Algazel retoma a caracterização lógica da noção de esse na forma das perguntas "an est" e "quid est" ${ }^{4}$ para posteriormente demonstrar que o esse não é essencialmente predicável em nenhuma categoria. A prova relativa à categoria da substância diz que se não houvesse diferença entre a substância de algo e a sua existência, então dizer que a substância existe seria o mesmo que dizer que a substância é substância. Como provas semelhantes podem ser feitas para cada uma das categorias, conclui-se que o esse se aplica a todas as categorias e que possui um significado que engloba todas as categorias. No entanto, dado que já foi provado que a unidade em questão não pode ser a univocidade, segue-se que deve haver uma unidade de significado diferente da univocidade. É precisamente isso que a Metaphysica de Algazel denomina ambiguidade.

Podemos finalmente retornar à questão de como interpretar, de um ponto de vista ontológico, a tese lógica da acidentalidade da existência. A precisão da resposta forçou os tradutores latinos a criar o neologismo "hanitas" 55 , que pode ser encontrado nas traduções latinas de Avicena e Algazel. Este último o utiliza em duas passagens fundamentais: ao caracterizar a relação entre acidentes e substância e ao determinar a natureza divina e a sua relação com os seres compostos. A primeira passagem encontra-se no contexto do debate sobre a divisão do esse nas dez categorias, enquanto a segunda configura uma investigação que vai para além do domínio categórico. Em ambos os casos, porém, o argumento gira em torno do par matéria e forma. ${ }^{56}$ Segundo a lição tradicional de Aristóteles no livro $Z$ da sua Metafísica, matéria e forma podem ser consideradas substâncias, sem implicar a existência de dois objetos existindo separadamente. Algazel aceita maneira de apresentá-las, sublinhando que nem a matéria pode existir sem forma, nem o contrário. ${ }^{57}$ O que existe, pelo menos no domínio sensível, é então o composto de matéria e forma, objeto da percepção sensível. Os elementos do composto não existem no sentido absoluto da palavra. Sua existência não é

${ }^{53}$ ALGAZEL, Metaphysica, p. 24 22-26: "In deffinicione autem coniunguntur genus, et differencia, esse igitur et ipsa equalia sunt, in quantum non habent diffinicionem, ipsa vero recipiunt descripcionem, sed esse minime, quoniam nichil est nocius quam esse per quod cognoscatur ipsum esse."

${ }^{54}$ ALGAZEL, Metaphysica, p. 25 17-20: "hoc autem manifestum est, ex hoc quod diximus scilicet quod questio an est, qua queritur de esse, alia est ab ea qua queritur quid est.”

${ }^{55}$ Nas traduções latinas de Avicena, encontramos a grafia “anitas”. O termo visa capturar o árabe "anniyya” cuja explicação mais frequente é dada VAN DER BERGH (1991, p. 529): “anniyya, terme abstrait formé sur la conjonction 'an ou 'anna «que», est la traduction littérale du terme aristotélicien to otı et désigne donc le fait qu'une chose est.” Para a história dessa expressão, ver D'ALVERNY, 1993.

${ }^{56}$ ALGAZEL, Metaphysica, p. 25 23-25: "Diversitas autem inter hanitatem, et quiditatem cognoscitur diffinicione intelligibili, non sensibili, sicut diversitas forme et hile."

${ }^{57}$ ALGAZEL, Metaphysica, p.16 8-10: "Hyle non habet esse in actu per se sine forma ullo modo; esse enim eius numquam est sine forma. Similiter forma non existit per se sine hyle." 
objeto de percepção sensível e deve ser inferida a partir das propriedades reais ou potenciais do composto. Assim, a existência da matéria é considerada como uma condição para explicar a potência. A matéria é, portanto, o princípio da potência e receptáculo das formas. A existência da forma explica a atualidade das propriedades da substância. A forma é, portanto, o princípio da atualidade. No entanto, os dois princípios têm apenas uma existência complementar. Existem apenas na sua composição. Numa palavra, a substância sensível não é um agregado, mas um único objeto composto por dois princípios. Evidentemente, portanto, a existência não pode ser, de um ponto de vista ontológico, uma forma atribuível à substância já constituída.

Dito isso, faz-se, então, necessário explicar como o conceito de existência pode ser aplicado às propriedades acidentais. Lembremos que, na ontologia de Avicena reproduzida por Algazel, o acidente é caracterizado como tendo um modo de ser tributário da substância. Ser um acidente significa existir em uma substância. No entanto, os acidentes possuem também essência. Todos apresentam uma natureza (brancura, negritude, etc.) sem serem chamados acidentes devido a esta natureza. São acidentes relacionados com os seus substratos..$^{58}$

Por conseguinte, deve concluir-se que os pares conceptuais "substância e acidentes" e "essência e existência” não se sobrepõem. O primeiro configura o domínio categórico e envolve objetos compostos de matéria e forma, ao passo que o segundo ultrapassa os limites dessa divisão. Ao último, podemos chamar transcategorial ou mesmo ultracategorial. Evidentemente, essa terminologia não faz parte do vocabulário técnico de Algazel, mas captura o espírito do seu texto. A expressão "transcategorial" refere-se ao fato de a distinção entre essência e existência não se limitar à categoria da substância, sendo, pelo contrário, aplicável a todas as categorias. A expressão "ultracategorial" expressa, por sua vez, a tese de que a distinção entre essência e existência é sempre aplicável aos seres compostos, mesmo que estes não sejam compostos de matéria e forma. Mas que tipo de composição poderia ser? A resposta a essa pergunta requer uma reflexão sobre como a Lógica de Algazel expõe as noções modais. É a interpretação das noções modais que permite, em última instância, explicar as relações entre as noções de essência e existência, relações que podem ser resumidas na famosa fórmula: há apenas um ser cuius hanitas est ipsa eius quidditas. ${ }^{59}$

Algazel oferece grosso modo uma dupla divisão de modalidades. A primeira, que propomos chamar "caracterização intrínseca das modalidades", é, na verdade, uma classificação ontológica dos seres de acordo com o modo de ligação de suas essências e existências. O quadro das modalidades intrínsecas é o seguinte:

- Ser necessário ${ }_{\text {def }}$ sua existência deve-se à sua essência;

- Ser impossível $=_{\text {def }}$ sua existência é proibida por sua essência;

- Ser possível $=_{\text {def }}$ sua existência não é nem necessária nem impossível por sua essência; ${ }^{60}$

Nos dois primeiros casos, as consequências ontológicas são tão óbvias que merecem uma denominação especial, respectivamente, debitum esse e prohibitum esse. Quanto aos possíveis, a existência é intrinsecamente neutra e a questão de saber se existem ou não deve ser colocada dentro de uma cadeia causal, ou seja, o

\footnotetext{
${ }^{58}$ ALGAZEL, Metaphysica, p. 26 17-21: "Unumquodque eorum [novem predicamentorum] habet in se essenciam suam, qua est id quod est. Convenit autem eis accidentalitas comparatione eorum in quibus existunt; nomen enim accidentalitas convenit eis respetu suorum subiectorum, non secundum id quod sunt."

${ }^{59}$ ALGAZEL, Metaphysica, p. $120^{7-8}$.

${ }^{60}$ ALGAZEL, Metaphysica, p. 46 18-25: "Dicemus igitur quod quicquid est cuius esse est a se ipso non ab alio, illud est debitum vel necesse esse; quicquid autem est non habens esse a se ipso illud vel est prohibitum in se, et est impossibile esse umquam, vel est possibile in se. Quod autem est debitum essendi est necesse esse; prohibitum autem essendi est necessarium non esse; possibile vero est id quod non sequitur necessario esse, vel non esse."
} 
seu ser é dependente de outro ser (esse eius est ab alio). É precisamente para dar conta da possibilidade intrínseca que Algazel propõe a segunda divisão, formulada em função das noções de existência e de causalidade. Chamemo-la "caracterização extrínseca das modalidades". O quadro é o seguinte:

- Ser necessário ${ }_{\text {def }}$ sua existência é a consequência de uma série causal;

- Ser impossível ${ }_{\text {def }}$ sua existência é impedida por uma série causal;

- Ser possível ${ }_{\text {def }}$ nem a sua existência nem a sua inexistência são consequência de uma série causal; ${ }^{61}$

Este esquema é rico em consequências, permitindo uma diferenciação clara entre, por um lado, a possibilidade inerente às essências e, por outro, a necessidade temporal das substâncias compostas. ${ }^{62}$ Assim, a mesma substância pode ser dita possível e necessária, uma vez que é considerada em dois aspectos distintos, sem alterar nada sobre a sua possibilidade intrínseca. O ser que, considerado em sua essência, é possível - o possível em si (possibile in se) - pode ser dito necessário quanto considerado em relação a sua causa, pois foi necessariamente causado, ou seja, é necessário propter alio. Ele é possível de um modo e necessário de outro. ${ }^{63}$ Logo, não é incompatível afirmar que toda substância que existe agora ou tenha existido é necessária e afirmar que a existência futura de substâncias é possível. Ou seja, o determinismo causal do passado não é uma condição suficiente para a afirmação do determinismo absoluto.

Voltemos agora à interpretação ontológica da existência como acidente. Observemos de início que Algazel é claro ao afirmar a simplicidade do ser intrinsecamente necessário. Trata-se do único ser simples e o único que pode ser causa em sentido primeiro. Todos os demais seres serão ao mesmo tempo compostos e causados. ${ }^{64}$ Assim, dado o caráter absolutamente geral desta última afirmação, conclui-se que mesmo as Inteligências, isto é, os objetos não compostos de matéria e de forma, são compostos. Estamos então perante um dos pontos nevrálgicos desta teoria: em que sentido os seres não compostos de matéria e forma podem ser ditos compostos? Eis a resposta:

Isso, portanto, enquanto é possível, é em potência, e enquanto é necessário, é em ato. A possibilidade, ele a possui por si (exse), a necessidade, por algo distinto de si (ex alio a se). Há, portanto, nele uma multiplicidade, de um algo que é semelhante à matéria e de outro que é semelhante à forma. Isso que é semelhante à matéria é a possibilidade e isso que é semelhante à forma é a necessidade, que é para ele a partir de algo distinto de si. $^{65}$

\footnotetext{
${ }^{61}$ ALGAZEL, Metaphysica, p. 46 28-476: "Esse autem ab alio habet tres respectus; unum ut si ponatur esse illud, a quo est quod est eius causa, causatum fuit debitum, eo quod premonstratum quod esse causati debet esse, existente causa. Aliud ut si ponatur causa non esse, ipsum causatum fit prohibitum. ( ... Tercium ut non consideretur an eius causa sit, vel non sit, sed consideretur ipsum tantum per se; habebit ergo ex se ipso tercium membrum scilicet possibilitatem."

${ }^{62}$ Esse esquema foi objeto de críticas por Averróis, 1961, p. 316: "Haec quidem additio apud me est superflua et error. Quoniam necessarium, quomodocunque positum fuerit, in eo quidem non est possibilitas omnino, et non reperitur aliquid habens unam naturam, ut dicatur de hac natura quod sit possibilis aliquo modo et necessaria aliquo modo. Quoniam declaraverunt homines quod necessarium nihil est possibile omnino. Possibile enim contradicit necessario."
}

${ }^{63}$ ALGAZEL, Metaphysica, p. 120 12-16: "Igitur secundum consideracionem quiditatis erit possibile essendi, et secundum consideracionem cause, erit necesse essendi eo quod ostensum est quod quicquid possibile est in se, necesse est propter aliud a se; habet igitur duo iudicia scilicet, necessitatem uno modo, et possibilitatem alio modo."

${ }^{64}$ ALGAZEL, Metaphysica, p. 120 5-9: "quoniam primus est unus et verus, eo quod esse eius est esse purum, cuius hanitas est ipsa eius quidditas, et quicquid est preter illum est possibile; esse autem omnis possibilis est preter suam quiditatem, sicut predictum est."

${ }^{65}$ ALGAZEL, Metaphysica, p. 120 5-23: "Ipsum igitur secundum quod est possibile, est in potentia, et secundum quod est necesse, est in effectu; possibilitas vero est ei ex se, et necessitas ex alio a se; est igitur in eo multitudo unius quidem quod est simile materie et alterius quod est simile forme. Quod autem est simile materie est possibilitas, et quod est simile forme est necessitas, que est ei ex alio a se." 
Na medida em que o significado da composição se baseia em uma analogia com o par "matéria e forma", não há outra possibilidade senão concluir que os objetos em questão são compostos por dois princípios complementares e interdependentes. Contudo, uma vez que os dois princípios só podem existir se o composto existir, não pode tratar-se de uma composição entre duae res. O que existe, portanto, é apenas uma coisa que é necessária se for considerada em relação à sua causa e que é possível se for considerada em relação à sua essência. Pelo que acabamos de ver, não é difícil compreender por que a Metaphysica Algazelis pode afirmar sem problemas que as duas maneiras de considerar as substâncias não materiais são distintas. Considerar algo em relação à série causal em que está inserido não é o mesmo que o considerar apenas em relação à sua essência.

Em resumo, Algazel propõe uma dupla caracterização da tese da acidentalidade da existência. De acordo com a Lógica, a existência é um acidente da essência porque é exterior a ela. O termo "acidente" é, portanto, utilizado em sentido lato: qualquer predicado que não pertença à essência de um sujeito pertence-lhe como um acidente. A Metafísica, por sua vez, oferece uma interpretação ontológica destinada a completar a interpretação lógica. Algazel demonstra que qualquer ser cuja essência não seja idêntica à sua existência é um ser possível e composto. A explicação da possibilidade é feita através de uma dupla caracterização das modalidades: intrínseca e extrínseca. Mas somente os seres intrinsicamente possíveis podem ser produzidos em uma série causal, ou seja, podem ser necessários por outro.

\section{Referências bibliográficas:}

AERTSEN,J. A. 1996. Medieval Philosophy and the Transcendentals: The Case of Thomas Aquinas. Leiden: Brill.

ALGAZEL. 1506. Logica et philosophia Algazelis Arabis. Venice: P. Liechtenstein. Reimpressão 1969. Frankfurt: Minerva.

ALGAZEL.1933. Algazels's Metaphysics: A Medieval Translation, edited by J. T. Muckle. Toronto: St. Michael's College.

ALGAZEL. 1963. Maqâsid al-Falâsifa o Intentiones de los filósofos, traducción, prólogo y notas por M. Alonso. Barcelona: Juan Flors Editor.

ALGAZEL. 1997. The incoherence of the philosophers, a parallel english-arabic text translated, introduced and annotated by M. E. Marmura. Provo: Brigham Young University Press.

ASHWORTH, E. J. 2008. Les théories de l'analogie du XIIe au XVIe siècle. Paris: Vrin.

AVERRÓIS. 1574. Epitome in librum Metaphysicae Aristotelis. Venetiis.

AVERRÓIS. 1961. Destructio Destructionum philosophiae Algazelis in the Latin Version of. Calo Calonymos, ed. B. H. Zedler, Milwaukee, Marquette University Press.

AVICENA. 1508. Logyca. In Auicenne perhypatetici philosophi ac medicorum facile primi opera. Venice. Caecilius Fabrianensis.

AVICENA. 1951. Livres des directives et remarques. Traduction avec introduction et notes par A. M. Goichom. Paris. Vrin.

AVICENA. 1977-1983. Liber de philosophia prima sive Scientia divina, édition critique de la traduction latine médiévale par S. Van Riet et introdution doctrinale par G. Verbeke. Leiden: E. J. Brill, 3. vols. 
AVICENA. 1986. Livre de la science, Volume I: Logique et Métaphysique, Volume II: Sciences Naturelles et Mathématiques, traduction M. Achena et H. Massé. Unesco: Belles Lettres.

AVICENA. 2018. Logyca. Texte latin, édition critique de la traduction médiévale par F. Hudry et introduction doctrinale par A. de Libera. Paris: Vrin.

BELLO, I. A. 1989. The medieval islamic controversy between philosophy and orthodoxy, Ijmâ' and Ta'wîl in the conflict between Al-Gazâlî and Ibn Rushd. Leiden: Brill.

CRUZ HERNANDEZ, M. 1997. Abû-l-Walîd Muhmmad Ibn Rûsd (Averroes): Vida, obra, pensamiento, influencia. Córdoba, Publicaciones Cajasur, segunda edición.

D’ALVERNY, M. T. 1993. “Anniya - anitas”. In M. T. D’Alverny, Avicenne en Occident. Paris: Vrin, chapitre X, p. 59-91.

D’ALVERNY, M. T. 1994. "Algazel dans l'Occident latin". In BURNETT, C. La transmission des textes philosophiques et scientifiques au Moyen Age. Aldershot: Variorum: VII, p. 3-24.

FILIPE, O CHANCELER. 1985. Philippi Cancellarii Summa de bono, edited by N. Wicki. Berne: Francke.

FOREST, A. 1956. La structure métaphysique du concret selon saint Thomas d'Aquin. Paris. Vrin.

FRANK, R. M. 1987-1989. “Al-Ghazâlîs's use of Avicenna’s philosophy”, in Revue des Etudes Islamiques 55-57, p. 271-285.

LIBERA, A. de. 1989. "Les sources gréco-arabes de la théorie médiévale de l'analogie de l'être". Les études philosophiques, 3/4: 319-45.

LOHR, C.H. 1965. "Logica Algazelis: Introduction and Critical Text”. Traditio 21: p. 223-90.

MARMURA, M. E. 1975. "Ghazali attitude to the secular sciences and logic". In HOURANI, G.F. Essays on islamic philosophy and science. Albany: State University of New York Press, p. 100-111.

MINNEMA. A. H. 2014. "Algazel Latinus: The Audience of the Summa theoricae philosophiae, 11501600”. Traditio, 69, p. 153-205.

SALMAN, D. 1935-1936. “Algazel et les latins”. Archives d'Histoire Doctrinale et Littéraire du Moyen Âge, 9-10, p. 103-127.

STORCK. A. 2005. "As noções primitivas da Metafísica segundo o Liber de Philosophia Prima de Avicena". Analytica, Rio de Janeiro, v. 9, n.2, p. 13-41.

STORCK. A. 2008. “Ens rationis e a natureza da lógica segundo Avicena”. Discurso, São Paulo, v. 38, p. 07-30. VAN DER BERGH, S. 1991. “Anniyya”. In Encyclopédie de l'Islam. Nouvelle Édition. Leiden: Brill, t. I, p. 529. ZEDLER, B. 1976. "Another look at Avicenna", The New Scholasticism 50, p. 504-21.

Recebido em 01 de julho de 2020. Aceito em 14 de janeiro de 2021. 